\title{
Atlético Nacional-Millonarios. Comunicación emotiva y localismo en el discurso del diario El Colombiano
}

\author{
Atlético Nacional-Millonarios. Emotive communication and localism \\ in the news speech of El Colombiano newspaper
}

César Augusto Gaviria Cuartas cagaviriac@ut.edu.co

http://orcid.org/0000-0003-0437-4395

Universidad del Tolima (Colombia)

\section{Resumen}

El presente artículo es producto del rastreo de elementos de comunicación emotiva contenida en textos informativos publicados en el periódico El Colombiano de Medellín (Colombia), acerca del clásico de fútbol entre Atlético Nacional de Medellín y Millonarios, de Bogotá (1). Para ello, esta indagación combinó metodológicamente el análisis del discurso y los modos retóricos en contextos de comunicación emotiva a partir de presupuestos teóricos de autores como Chaim Perelman, Christian Plantin y Teun Van Dijk para la localización no sólo de elementos directos de emoción sino también de indicios situacionales de emoción que se conectan con cuestiones identitarias de orden local. En general se estableció que el empleo de datos e informaciones relacionadas con la confrontación protagonizada por los actores directos del fútbol (jugadores, entrenadores, directivos), antes y después de cada juego, presenta sesgos discursivos que incentivan una visión particularista de la realidad en esta región. En otras palabras, los términos y alusiones emotivas en estos artículos periodísticos acuden, 
explícita o implícitamente, a lugares comunes que se encuentran en la consciencia protonacional de lectores del departamento de Antioquia.

Palabras clave: Discurso periodístico; comunicación emotiva; medios impresos; protonacionalismo.

\section{Abstract}

This article is the product of searching of elements of emotional communication contained in informative texts published in the newspaper El Colombiano, of Medellín (Colombia) about classic soccer game Atlético Nacional, from Medellín, and Millonarios, from Bogotá. For this, this inquiry methodologically combined the analysis of discourse and rhetorical modes in contexts of emotional communication from the theoretical assumptions of authors such as Chaim Perelman, Christian Plantin and Teun Van Dijk to stablish not only direct elements of emotion but also to find situational signs of emotion that connect with identity issues of local nature. In general, this article established that the use of data and information related to the confrontation between the direct players of soccer (players, coaches, managers), before and after each game, presents discursive biases that encourage a particularist vision of reality in this region. In other words, the emotive terms and allusions in these newspaper articles, explicitly or implicitly, refer to common places that are in the protonational consciousness of Antioquia readers.

Keywords: Journalistic speech; emotive communication; print media; protonationalism.

En el mundo periodístico se insiste mucho que la noticia es, por antonomasia, el género de mayor neutralidad informativa frente a otros géneros en los que existe la posibilidad de despliegue de mensajes abiertamente intencionados y persuasivos. Heredera del positivismo del siglo XIX, la estructura de la noticia ha seguido las directrices de asepsia y distanciamiento (2), contenidas en un modelo de pirámide invertida que se ha convertido "no sólo en dogma sino en ritual" (Miralles, 2007: 38). No obstante, estas pretensiones de objetividad se desvanecen cuando se sondea el carácter retórico implícito o explícito de todo artículo noticioso producto de diversas calificaciones, categorías gramaticales, modos de expresión del pensamiento y enfoques por parte del informador, aspectos que fueron tenidos en cuenta en el 
análisis de un conjunto de textos informativos publicados en el periódico El Colombiano, de Medellín (capital del departamento de Antioquia), entre 2002 y 2010 acerca del clásico futbolístico entre Atlético Nacional de Medellín y Millonarios, de Bogotá, uno de los partidos que genera mayor interés entre el público que sigue el campeonato colombiano de primera división. Desde su creación, El Colombiano se ha caracterizado por llevar a sus lectores información favorable a sectores partidistas que impulsan principios morales e ideológicos que corresponden con la ascendencia conservadurista de la provincia de Antioquia (3). Estos principios hunden sus raíces en la fuerte tensión política entre el centralismo y el federalismo que a lo largo del siglo XIX amenazó con fragmentar el territorio colombiano. En el caso particular de Antioquia, su desarrollo económico motivó la defensa de un modelo federalista que garantizara la permanencia de formas de ascenso social, el aprecio por la pujanza en el trabajo, el espíritu expansionista en los negocios, la preponderancia de la fe católica, los avances en el sistema educativo, y la cohesión cultural basada en lealtades familiares y territoriales (4). Hoy día la síntesis del carácter de esta región se encuentra en el fenómeno histórico de la colonización antioqueña (5) que ha servido de inspiración para el denominado "mito de la raza paisa" (Restrepo, 1995) que pervive en los relatos de gran parte de los habitantes de este departamento.

Aunque la Constitución Nacional de 1886 inició un fuerte proceso de centralización del sistema político nacional, la Constitución de 1991 matizaría las tensiones entre el gobierno central y las administraciones locales al conceder a Colombia el carácter de "República unitaria, descentralizada, con autonomía de sus entidades territoriales, democrática, participativa y pluralista". No obstante, las cuestiones de orden constitucional no han sofocado la reaparición de reclamos con visos de secesionismo cada que ocurren hechos que sectores de la elite política de Antioquia -establecida en Medellín-, consideran ataques contra la dignidad de los habitantes de su territorio. Recientemente, la disputa limítrofe entre los departamentos de Antioquia y Chocó por la ubicación del corregimiento de Belén de Bajirá en mayo de 2017, significó un nuevo reclamo de dirigentes antioqueños que expresaron en medios de comunicación masivos de la región -El Colombiano, el más importante de ellos-, sus inconformidades frente a la posición del gobierno nacional en esta disputa.

Para Luis Anibal Gómez (1982), el sentido u orientación que recibe un acontecimiento, de cualquier índole, a través del tratamiento técnico noticioso, puede estar determinado por las tendencias ideológicas con los que el medio entiende la realidad de lo sucedido. De igual manera, la noticia no necesariamente revela la autenticidad de los hechos divulgados sino que adquiere valor según el marco referencial de cada informador y su lealtad a la línea editorial del 
medio en el que labora. De allí que pueda afirmarse que los artículos noticiosos en realidad proporcionan opiniones, "a pesar de la creencia ideológica de muchos periodistas en el sentido de que la noticia sólo debe presentar los hechos y no la opinión" (Van Dijk, 1990: 19). Esto se comprueba al comparar las descripciones informativas de un mismo hecho en dos medios de comunicación distintos o cuando se hace análisis crítico de sucesivas publicaciones noticiosas de un solo medio acerca de una temática específica, cuestión que ratifica Chaim Perelman (1997) cuando afirma que la objetividad periodística expresa en realidad una retórica informativa particular.

Cognitivamente, la noticia de prensa recurre a perspectivas de mundo ya conocidas por los integrantes de grupos sociales específicos, facilitando la memorización de datos 0 proposiciones que corresponden con dichas perspectivas. La aceptación de las proposiciones de una noticia está condicionada por su concurrencia con otros conocimientos y creencias que ya se poseen en torno a cuestiones de identidad cultural, costumbres, gustos ideológicos, entre otros. Es decir, la cercanía de las proposiciones de información nueva en relación a las proposiciones previamente aceptadas es requisito obligatorio de cualquier pretensión persuasiva. "Se supone que los argumentos explícitos o implícitos influyen en el trabajo cognitivo que afrontamos cuando consideramos la aceptación de una proposición afirmada por el hablante" (Van Dijk, 1990: 125). Esto significa, en términos retóricos, que la eficacia del orador recae en el hecho de que conozca bien lo que su auditorio sabe o piensa, y también lo que ignora; y que sepa escoger las premisas "en función de cuáles sean las preferencias y valores del público al que se aspira a persudir" (Bordes Solana, 2011: 33). En sentido inverso, los modelos mentales de los destinatarios y sus consideraciones terminan correspondiendo con las simplificaciones contenidas en la estructura discursiva de los acontecimientos informados por el periodista.

Se reconoce, entonces, que en una noticia se hace un uso intencionado del contenido de cada término en favor del vínculo entre las representaciones e imaginarios del escritor con los de sus lectores. Y para que los integrantes de una sociedad emitan e interpreten de la misma manera cuestiones públicas debe existir una confluencia en el significado fundamental del mensaje. Tácitamente este pacto de lectura entre productores y receptores hace creíble o verídico todo lo que divulga el vehículo mediático -en este caso el papel-. Un "contrato" sustentado en la certeza de las noticias divulgadas. Esto significa que la confianza depositada en ellas motiva a entenderlas sin dificultades, a no pensar en segundas intenciones y mucho menos a 'leer entre líneas' (McQuail, 1998). Si tal acuerdo no existiese, el consenso se vería obstaculizado por un entendimiento incompleto o distorsionado entre los agentes del proceso comunicativo. 
Es así como surgen las afinidades en torno a determinadas creencias y a la fuerza afectiva, a valores e intereses que contribuyen "a la convicción y a la resistencia de una opinión colectiva sostenida por un pueblo" (Crespi, 2000: 90). Precisamente, las manifestaciones discursivas de localismo incentivan lo que podría denominarse una consciencia nacional/regional que sirve de insumo a cualquier reivindicación particularista. Eduardo López-Aranguren (1995) afirma que esta consciencia posee tres niveles analíticamente diferenciables: percepciones, explicaciones y aspiraciones. Dichos niveles se definen así:

\begin{abstract}
Las percepciones consisten en un percatarse, darse cuenta o ponerse al corriente de las diferencias -incluidos los llamados 'hechos diferenciales' y las desigualdades socioeconómicas- existentes entre unas regiones y otras. Las explicaciones identifican las causas y los mecanismos de perpetuación de las diferencias y desigualdades percibidas, y proporcionan interpretaciones de las mismas. $\mathrm{Y}$ las aspiraciones que siempre arrancan de un sentimiento de privación, indican las metas y los objetivos nacionalistas o regionalistas a conseguir (López-Aranguren, 1995: 42).
\end{abstract}

Esto indicaría que el discurso informativo de matiz localista echa mano de evocaciones lingüísticas contenidas en el universo discursivo común (Crespi, 2000) que surge de estos tres de niveles de consciencia, siempre latentes en colectivos que poseen fuerte carácter identitario. Un universo discursivo común y localista que podría verificarse en las reclamaciones separatistas, implícitas o explícitas, de colectividades asentadas en distintos lugares del mundo. Cataluña, Escocia y Kurdistán son algunas de las regiones del mundo que han hecho persistentes sus deseos de total autonomía administrativa y política. No obstante, existen otros particularismos -menos insistentes y no por ello inexistentes-, que manifiestan cada tanto tiempo sus "lazos protonacionales" (Hobsbawm, 1998) en medios masivos de comunicación.

Vale reiterar que la comunión en torno al mismo idioma no es el único elemento base de la exaltación localista sino, además, la existencia de un acuerdo -al menos implícito- con relación "a las asunciones, las expectativas, las implicaciones, las asociaciones y los sentimientos latentes que esas palabras tienen" (Crespi, 2000: 101). Lo anterior ha servido a la sociología de las emociones (Bericat, 2000) y la argumentación de la comunicación emotiva (Gutierrez y Plantin, 2010) para mostrar que las emociones son, en buena medida, construcciones discursivas que tienen un fondo de racionalidad en tanto que son canalizadoras de los sistemas de representaciones e imaginarios sociales existentes. En muchas ocasiones -dice Castellslas emociones controlan el comportamiento social proyectando el futuro a partir de la conexión entre sentimientos del pasado con acontecimientos del presente (2008). Y tal como lo explica 
Guibernau (1996), las expresiones reivindicativas de carácter nacionalista suelen acudir a discursos inspirados en un pasado común, en las coincidencias del presente y en la consolidación de un proyecto colectivo a futuro.

\section{Comunicación emotiva y retórica}

Para el análisis discursivo y retórico de la emoción en noticias acerca del clásico NacionalMillonarios, publicadas en El Colombiano, de Medellín, se asumió una perspectiva que se enfocara en precisar los ascendientes mediáticos de los mensajes que predominan entre los destinatarios. En particular, el análisis fue encaminado a precisar en un grupo de artículos de prensa los principios (o topoi) que aseguran "la coherencia del discurso que conmueve" (Gutiérrez y Plantin, 2010: 50). Para ello, se partió de la consideración de que los argumentos emotivos no son una creencia débil o una verdad poco rigurosa, sino, por el contrario, "la materia de nuestra vida cotidiana, el cemento de nuestra adhesión a la vida y la base de nuestras elecciones más esenciales" (Breton, 2014: 17).

En general, se argumenta una emoción cuando el discurso justifica una vivencia (Gutiérrez y Plantin, 2010). El discurso es entendido, entonces, como una práctica social que se concreta en conjuntos de argumentos y pruebas, destinados a "esquematizar o teatralizar" de una cierta manera "al ser y al deber ser políticos ante un público determinado" con vistas a intervenir sobre este público (Gutiérrez y Plantin, 2010: 47). En este sentido, el propósito de un orador como lo es un periodista deportivo- sería hacer que su audiencia experimente algún tipo de sentimiento y convertir las emociones experimentadas en la vida real en herramientas para canalizar los juicios de los receptores hacia el tema central, la posición frente a las personas involucradas y las circunstancias correspondientes. Es más, en la estructuración del mensaje retórico el autor (orador, escritor) determina qué elementos reales (los hechos y las verdades, por ejemplo) y preferibles (los valores y los lugares comunes, por ejemplo) enuncia en su discurso. Es decir, que el autor selecciona y recrea los aspectos de la realidad aludida para persuadir al destinatario de su discurso con base en cuestiones particulares.

La persuasión actúa sobre aspectos de la vida social en los que no es posible establecer acuerdos universales, porque no se puede llegar hasta ellos para desentrañarlos y extraer su verdad, sólo su posibilidad. Estos aspectos abarcan grandes espacios de la vida social en los que la opinión es fundamental (Santamaría, 1990: 41). 
Esta conjugación de razón y emoción sirve para sustentar que la comunicación emotiva -a diferencia de la comunicación emocional- apunta a la introducción intencional y estratégica de las emociones por parte de los productores de mensajes (Caffi y Janney, 1994), quienes buscan la manera de conectar sus discursos con las representaciones e imaginarios que se acercan a la emocionalidad de sus destinatarios. Con esto, los análisis de comunicación emotiva contenida en discursos periodísticos dilucidan parte del andamiaje de las relaciones sociales, de las identidades y de los conflictos, intentando entender "cómo se expresan los diferentes grupos culturales en un momento histórico, con unas características socioculturales determinadas" (Calsamiglia y Tuson, 2001: 16).

Años atrás se pensaba que razón y emoción eran dos opuestos irreconciliables de la naturaleza humana. Ello hizo que las emociones fueran de cierta manera despreciadas a partir del siglo XVII debido a que la filosofía privilegió lo abstracto, lo universal y lo atemporal como rechazo a todo aquello que estuviera relacionado con lo instintual y lo subjetivo. Por mucho tiempo se abandonó el postulado de Aristóteles en el que reconocía que "los factores emocionales no son ajenos al proyecto de una retórica basada en razonamientos y que, de hecho, es posible acceder a una descripción objetiva de enunciados subjetivos en los márgenes de una doctrina de la causalidad psicológica" (Aristóteles, citado por Fonseca y Prieto, 2010: 81).

Sería la obra de Perelman, en la década de 1960, la que marcaría un retorno (y una explosión) de los estudios sobre retórica y su relación con contextos culturales y sociopolíticos específicos relacionados con los usos del discurso público, no sólo debido al auge de las técnicas de comunicación y de las estrategias de inducir a la gente a hacer o pensar algo, sino también debido "al mejor conocimiento de los problemas que anidan en la trama cognitiva y discursiva del dar y pedir razón de algo a alguien o ante alguien" (Vega Reñón, 2013: 11). En este sentido, los razonamientos persuasivos no son ni deducciones formalmente correctas ni inducciones que van de lo particular a lo general, "sino argumentaciones de toda especie que pretenden ganar la adhesión de los espíritus a las tesis que se presentan a su asentimiento" (Perelman, 1997: 12). Es decir, la aceptación o movilización en torno a ciertas afirmaciones no se logra impulsando una idea puramente abstracta, sino "que la audiencia sienta como verdadero el estado emocional en cuestión, es decir, que esté viviendo un estado emocional inducido como verdadero" (Fonseca y Prieto, 2010: 85).

Vale aclarar que "la apelación a la emoción tiene lugar legítimo, incluso importante en el diálogo persuasivo" (Walton, 1992), lo que no debe entenderse como la validación del uso falaz 
de las emociones (Gutiérrez y Plantin, 2010: 48), ni como el ejercicio de una retórica sin disciplina ética (Bordes Solanas, 2011). Para Walton, el análisis de la argumentación emotiva sirve para determinar el compromiso profundo o velado que el argumentador sólo conoce como "corazonadas". Aunque la argumentación de la emoción puede llevar a conclusiones apresuradas basadas en los sesgos personales, las apelaciones a la emoción pueden ser útiles y correctas en argumentación porque

puede conducir a un argumentador hacia la resolución de un conflicto de opinión por la carga de la prueba o el peso de la presunción. Las corazonadas pueden reflejar la experiencia, la sabiduría o los mejores instintos del argumentador. Como tal, los argumentos basados en las emociones no son decisivos o absolutos, pero pueden conducir la línea de argumentación en una dirección favorable (Walton, 1992: 27).

\section{Elementos de la metodología}

Todo lo anterior fundamenta la idea que el periodista deportivo, a través de su producción textual, cumple una labor de orientador de opinión que se muestra como justa o legítima, al tiempo que actúa sobre los registros sentimentales que unifican los puntos de vista de su público, unión que no se conseguiría si se basara únicamente en la razón (Sauvy, 1971). Este informador no trata de convencer sino de persuadir razonablemente acerca de noticias que se relacionan con presuposiciones que se hayan preconcebidas en los receptores. Lo que significa que esta indagación no pretendió establecer la verdad o la falsedad de las afirmaciones de los periodistas deportivos, sino la argumentación implícita o explícita de exposiciones informativas que aluden estratégicamente a adhesiones o aversiones que son válidas en el contexto sociopolítico en el que son divulgadas.

En un modelo silogístico, de premisas y conclusiones, las primeras (con las cuales están familiarizados los lectores) fácilmente llevan a deducir las segundas. En palabras de Perelman: "la transferencia de la adhesión no se realiza sino estableciendo una solidaridad entre las premisas y las tesis que uno se esfuerza por hacer admitir" (1997: 43). Si el lector ya conoce el tema, es más fácil para él no sólo comprender las respectivas oraciones del texto sino las alusiones implícitas y explícitas a las cuestiones mencionadas por el escritor. Por ello, Gutiérrez y Reyna (2015) han puntualizado que los argumentos emotivos se manifiestan de manera directa e indirecta. 
En primer lugar, la expresión directa surge en los enunciados directos de emoción. En este primer caso, es un enunciado que une a un experimentador con una expresión de emoción por ejemplo, "qué alegría!"-. También puede abarcar la causa de la emoción -por ejemplo, "esto me alegra"-. Con esto el individuo "experimentador" hace notar tal o cual estado psicológico. De allí que primero sea necesario determinar quién se supone que experimenta qué; saber cuál es la conclusión que se persigue (la emoción que se quiere construir argumentativamente); y los tipos de razones ofrecidas para apoyar estas conclusiones.

Por otra parte, la expresión indirecta corresponde a la emoción implicada en los enunciados. Ella puede manifestarse de dos maneras: una, a través de los modos de comportamiento característicos de una persona emocionada. Y dos, a través de los "inductores estereotipados" que reconstruyen la situación bajo un formato narrativo/descriptivo que conduce a una clase particular de emoción. En este último caso, se trata de hallar lo que Christian Plantin (Gutiérrez y Reyna, 2015) ha denominado los patemas, es decir los indicios indirectos de las emociones que ayudan a la reconstrucción de la emoción transmitida.

Plantin sugiere una lista preguntas que sirven para determinar las orientaciones emocionales de los enunciados. Ellas son: ¿qué? (posición del ser o del acontecimiento); ¿quién? (tipo de ser afectado); ¿cómo? (correspondencia entre los dominios en los que la emoción es estabilizada socialmente); ¿cuándo? (modo de construcción temporal); ¿dónde? (modo de construcción espacial); ¿cantidad/intensidad?; ¿causa/agente?; ¿consecuencia?; ¿posibilidad de control por el lugar psicológico?; ¿conformidad o incompatibilidad con las normas y los valores del lugar psicológico?; ¿distancia del acontecimiento al lugar psicológico?.

Las mencionadas orientaciones emocionales de Plantin se encuentran contenidas en la propuesta de análisis del discurso noticioso propuesta por Teun Van Dijk (1990). Para el autor, cualquier artículo periodístico adquiere características propias de un esquema argumentativo basado en una serie de premisas que llevan a una conclusión informativa. En ese sentido, la admisión de la noticia parece residir en las condiciones que tienen que ver con subrayar la naturaleza factual de los sucesos tales como la veracidad de la descripción y la cercanía del reportero a los sucesos narrados.

De manera similar, las informaciones con testigos en forma de entrevistas pueden utilizarse como sustitutos necesarios de las observaciones propias del reportero. Los informes de lo que la gente ha visto con sus propios ojos se consideran más cercanos a la verdad que los rumores (Van Dijk, 1990: 129). 
Sin embargo, Van Dijk aclara que la retórica periodística no se limita a las figuras usuales del habla. Más bien, se utilizan los elementos estratégicos que favorecen la veracidad, la plausibilidad, la corrección, la precisión y la credibilidad, tales como las cifras, las fuentes, los testigos, las autoridades de distinta índole. Esto significa que el análisis retórico del texto informativo "no puede ser completamente independiente de un análisis semántico e ideológico del discurso periodístico" (1990: 138), afirmación que sustenta un listado de estrategias persuasivas que señalan aspectos de la macroestructura de la noticia. Ellas son:

1. Descripciones directas de los acontecimientos.

2. Evidencias de testigos cercarnos, o evidencias de otras fuentes fiables (autoridades, personas respetables, especialistas).

3. Señales de precisión y exactitud (cifras, datos exactos del acontecimiento, etcétera).

4. Citas de opiniones de fuentes relacionadas con el acontecimiento.

5. Descripciones de acontecimientos previos, o predicciones de consecuencias posibles 0 reales.

6. Uso de hechos dentro de modelos situacionales bien conocidos.

7. Utilización de argumentos y conceptos con los que se está familiarizado.

Con base en lo anterior, esta indagación concatenó heurísticamente los patemas planteados de Plantin con la propuesta de Van Dijk acerca de los atributos macroestructurales de la noticia. Ello dio como resultado el siguiente paralelismo (Tabla 1) que se tomó como guía de análisis:

\begin{tabular}{l|l}
\multicolumn{1}{c|}{ Van Dijk } & \multicolumn{1}{c}{ Plantin } \\
\hline Descripciones directas de los acontecimientos. & ¿Qué? ¿Quién? \\
\hline $\begin{array}{l}\text { Evidencias de testigos cercarnos, o evidencias } \\
\text { de otras fuentes fiables }\end{array}$ & ¿Cómo? ¿Cuándo? ¿Dónde? \\
\hline Señales de precisión y exactitud & ¿Cantidad/intensidad? \\
\hline Citas de opiniones de fuentes relacionadas & ¿Causa/agente? \\
\hline con el acontecimiento & \\
\hline
\end{tabular}


Descripciones de acontecimientos previos, o predicciones de consecuencias posibles o reales

Uso de hechos dentro de modelos situacionales bien conocidos

Utilización de argumentos y conceptos con los que se está familiarizado
¿Consecuencia?, ¿posibilidad de control por el lugar sicológico?

¿Conformidad o incompatibilidad con las normas y valores?

¿Distancia del acontecimiento al lugar sicológico?

Tabla 1. Elaboración propia.

\section{Análisis de resultados}

En general, los hallazgos de esta indagación confirman la existencia de comunicación emotiva de énfasis localista en los textos de noticias deportivas acerca del clásico Nacional-Millonarios, una comunicación que pretende ser efectiva en tanto se construye sobre aspectos discursivos compartidos por el periodista y los lectores a los que se dirige. Es más, cuando el informador divulga un hecho noticioso, existe una intencionalidad emotiva en la que se combinan elementos identitarios del contexto que rodea la producción del escrito y la estructura propia de los escritos publicados.

Aunque el tema político no se menciona en los textos informativos acerca del encuentro futbolístico en cuestión, es un factor que refuerza las insinuaciones de carácter regionalista de El Colombiano en las informaciones sobre este clásico, en especial si se tiene en cuenta que el contexto de producción de los artículos analizados correspondió con los dos períodos presidenciales de Alvaro Uribe Velez, reconocido político antioqueño de fuerte influencia en la opinión pública regional y nacional en las últimas décadas. En particular, los artículos seleccionados coincidieron con hechos políticos como la controversia nacional en torno al rescate militar de secuestrados (uno de ellos, el asesinado gobernador de Antioquia, Guillermo Gaviria Correa); los cuestionamientos de directivos de la empresa de transporte Transmilenio, de Bogotá, a la implementación del Sistema Metro en Medellín; la exequibilidad de la reelección inmediata por parte de la Corte Constitucional en favor de Uribe Vélez; y las investigaciones penales por parte de la Corte Suprema de Justicia y la Fiscalía General de la Nación a renombrados líderes antioqueños oficialistas (entre ellos varios parlamentarios y el director de la Fiscalía seccional Antioquia) por sus vínculos con grupos paramilitares. 
Específicamente, las noticias deportivas de El Colombiano contienen proposiciones en torno al clásico entre "verdes" y "azules" -en alusión a los uniformes de Nacional y Millonarios- que reeditan el sentimiento de personalidad diferenciada en los lectores de la región antioqueña, a partir de las menciones a la rivalidad de cada encuentro del equipo de esta zona del país frente al equipo capitalino. Titulares como "Los duros del verde se miden a Millos" ( 1 de mayo de 2005) o "Nacional dejó herido a Millos" (25 de septiembre de 2008) son muestra de ello.

A pesar que cada artículo alude en mayor o menor medida a la tradición, la jerarquía y la experiencia de ambos equipos, se mencionan superficialmente las virtudes del equipo bogotano para resaltar especialmente los méritos de Nacional, quien es exaltado como gran representante de esta región en la competición nacional de fútbol. Así queda expresado en la primera frase de la noticia publicada el 19 de octubre de 2005: "En las malas Nacional siempre ha demostrado su casta y en esta ocasión los jugadores tratarán de ser fieles a ese principio". La intención es engrandecer al equipo antioqueño, o por lo menos, mostrar su capacidad para superar las adversidades del momento. Ello se muestra en el artículo titulado "A Nacional le llegó la hora de la verdad" (29 de marzo de 2008) en el que se señala el bajo rendimiento del equipo. El periodista afirma que la "familia verdolaga" está inquieta porque los resultados no son los mejores. Los hinchas "se dan golpes de pecho" y las directivas tienen "los pelos de punta" porque ser penúltimos en la tabla "no es la posición que merece" el equipo, razón por la cual se espera que los jugadores de Nacional cumplan el deber de sobreponerse a la mala campaña.

Precisamente, la referencia a características personales, familiares o deportivas de ciertos jugadores de Nacional sirven no sólo para encarnar el presente del equipo -sus fortalezas o debilidades-, sino para generar expectativa antes de cada partido o hacer balance del rendimiento del equipo luego de jugados los encuentros. Tal fue el caso de los cálculos renales de un delantero de Nacional para señalar el mal juego del equipo, la presencia de la familia de un volante durante el partido para inspirar el deseo de salir avante en el campeonato, o el anuncio del futuro hijo de uno de sus defensas como alusión al retorno del equipo a la senda victoriosa.

En este mismo sentido, la información basada en afirmaciones por parte de algunos jugadores -como aquel que afirmó defender "a muerte" la camiseta del equipo- se convierte en muestra de la carga emotiva que el periodista imprime al escrito noticioso. Ejemplo de ello también es la noticia titulada "Nacional-Millonarios, otra vez clásico", del 17 de marzo de 2003, en donde se destaca la figura del juvenil defensa Carlos Díaz quien "no se cansa de mencionar a su mamá" 
cuando recuerda sus inicios en el fútbol. Asimismo, el periodista describe al jugador como "todo entrega y corazón", añadiendo además su fervor a la lectura permanentemente de la Biblia.

Estos artículos noticiosos emplean términos y enunciados que invocan conocidas imágenes relacionadas con la identidad provincial de muchos lectores de El Colombiano, tales como el ámbito familiar, la reverencia a los ascendientes "montañeros", la devoción católica y el espíritu emprendedor de los nacidos en Antioquia. Incluso se encuentra en varios de estos textos el uso de algunas expresiones de la jerga "paisa" (propia de la región antioqueña), como herramienta de reforzamiento de dicho imaginario. Es el caso de la noticia "Reencuentro con fuerza positiva" (7 de marzo de 2009) en el que se menciona el retorno de la hinchada de Nacional al estadio luego de dos fechas de sanción al escenario de Medellín. En este artículo el periodista afirma que el "parcero brasilero" Baiano, defensa extranjero que tiene "el honor" de llevar el brazalete de capitán del equipo, ha debido aplazar los placeres de vivir la ciudad -tales como degustar la bandeja paisa y visitar lugares turísticos de Medellín, como la Plaza Botero o el Parque Explora-, para concentrarse en llevar al "barco nacionalista, ojalá a un mejor puerto". Finalmente hay que decir son muchos los artículos en los que las descripciones del contexto específico de cada partido muestran la retórica de un discurso colmado de elementos vivenciales ocurridos durante los encuentros, pero difícilmente apoyado en declaraciones reflexivas del juego por parte de especialistas del deporte. Por ejemplo, en la nota periodística del 20 de octubre de 2005 titulada "Nacional respiró frente a Millonarios" se señala que una "fría noche" bogotana y una "gigantesca luna pintada de blanco" presenciaron el juego en un estadio en el que Nacional "juega de local". En "el verde de Antioquia", los defensas centrales fueron "las dos grandes torres" que impidieron las intenciones "azules". Así mismo, en Nacional, los jugadores Humberto Mendoza y Hugo Morales fueron "magistrales cobradores" de tiros libres que ayudaron a lograr un positivo resultado. Sin embargo, en ningún momento del escrito el exceso de adjetivos fue matizado con análisis por parte de analistas del fútbol. A manera de síntesis, se registra en la Tabla 2 los hallazgos de esta indagación:

\begin{tabular}{ll|ll}
\multicolumn{1}{c|}{ Criterios de análisis } & \multicolumn{2}{|c|}{ Discurso periódico El Colombiano } \\
\hline $\begin{array}{l}\text { Descripciones directas de los } \\
\text { acontecimientos }\end{array}$ & $\begin{array}{l}\text { El detalle de jugadas significativas del partido y } \\
\text { acciones de jugadores destacados }\end{array}$ \\
\hline $\begin{array}{l}\text { Evidencias de testigos cercarnos, o } \\
\text { evidencias de otras fuentes fiables }\end{array}$ & $\begin{array}{l}\text { Entrevistas a jugadores o técnicos, } \\
\text { predominantemente de Nacional }\end{array}$ &
\end{tabular}




\begin{tabular}{|c|c|}
\hline Señales de precisión y exactitud & $\begin{array}{l}\text { Circunstancias previas del partido, número de } \\
\text { asistentes al encuentro, goles acumulados, etcétera. }\end{array}$ \\
\hline $\begin{array}{l}\text { Citas de opiniones de fuentes } \\
\text { relacionadas con el acontecimiento }\end{array}$ & $\begin{array}{l}\text { Rara vez se cita a especialistas del fútbol o a } \\
\text { dirigentes deportivos }\end{array}$ \\
\hline $\begin{array}{l}\text { Descripciones de acontecimientos } \\
\text { previos, o predicciones de } \\
\text { consecuencias posibles o reales }\end{array}$ & $\begin{array}{l}\text { La ubicación del equipo en la tabla de clasificación } \\
\text { antes y/o después del partido }\end{array}$ \\
\hline $\begin{array}{l}\text { Uso de hechos dentro de modelos } \\
\text { situacionales bien conocidos }\end{array}$ & $\begin{array}{l}\text { Alusiones a la familia de los jugadores, a cuestiones } \\
\text { de salud de los jugadores, a situaciones cotidianas, a } \\
\text { lugares turísticos de Medellín, a la fe católica o a la } \\
\text { culinaria paisa }\end{array}$ \\
\hline $\begin{array}{l}\text { Utilización de argumentos y conceptos } \\
\text { con los que se está familiarizado }\end{array}$ & $\begin{array}{l}\text { "contienda", "armas", "herido", "contra las cuє } \\
\text { y otros de índole combativa o revanchista. }\end{array}$ \\
\hline
\end{tabular}

Tabla 2. Elaboración propia.

\section{Conclusiones}

El análisis de los artículos noticiosos publicados en El Colombiano acerca del cotejo futbolístico entre Atlético Nacional y Millonarios muestra que el propósito general de la comunicación emotiva contenida en esta retórica informativa es que el lector conciba el desempeño del equipo "verdolaga" en el campeonato -particularmente en las contiendas futbolísticas frente al equipo capitalino- como símbolo de la preservación de los intereses y aspiraciones de Antioquia.

En tal sentido, los esquemas periodísticos de persuasión en los que el periodista deportivo se apoya (como cualquier otro orador) utilizan frecuentes simplificaciones inspiradas en cuestiones identitarias de los receptores que el informador tiene en mente -al menos de forma tácita-. Es sabido que la retórica del discurso tiene que ver con el modo en que se dicen las cosas, y con la intención del orador para que el auditorio coincida con el esquema situacional planteado por él. Y si el orador no quiere fracasar en su misión, debe partir de premisas que gocen del beneficio de una adhesión suficiente tales como las representaciones y los imaginarios predominantes en el público destinatario, lo que de paso se podría convertir en 
apelaciones a los lazos protonacionales que cohesionan a grupos culturales específicos. Ello equivale a decir que el informador de fútbol de El Colombiano apuntala sus escritos en la creencia colectiva de que Atlético Nacional se juega en cada encuentro el honor de toda una región.

Justamente, el registro grandilocuente de datos de lo local, las referencias a rasgos particulares y las figuraciones relativas a valores enraizados en los habitantes de Antioquia son el trasfondo nacionalista del contenido emotivo de los textos informativos que usan los hechos ocurridos en cada clásico de fútbol para la defensa latente y permanente de un proyecto cultural regional que se insinúa inigualable. Con esto, el "contacto de los espíritus" del proceso comunicativo establecido a través de los textos noticiosos acerca del clásico Atlético Nacional-Millonarios, aportaría a la cotidiana reedición de la perspectiva apologética de la consciencia nacional/regional de los antioqueños.

Basados en el universo discursivo común relativo a la "raza paisa", los textos noticiosos analizados establecen una conexión entre los lectores y los periodistas deportivos que refuerzan sus particularismos. De allí que al lector se le haga fácil entender no sólo las proposiciones globales del texto noticioso sobre fútbol, sino las menciones implícitas y explícitas de la información ofrecida por este tipo de notas mediáticas. Así, los datos propios de la noticia publicada sirven al destinatario de noticias futbolísticas de El Colombiano para renovar viejos modelos de interpretación de la información y elaborar nuevas formas de significación. No obstante, hay que decir también que el discurso noticioso acerca de estos clásicos futbolísticos tiende más a lo primero que a lo segundo, sobre todo si lo que pretende es la generación de emoción localista en sus lectores con base en el imaginario aceptado por la mayor parte de este público.

Lo anterior confirmaría que los razonamientos fundados sobre valores concretos suelen ser característicos de sociedades tradicionalistas que enaltecen la conservación de valores típicos de su etnia, religión o nación. Si tenemos en cuenta que en el escenario mediático se proyectan las imágenes de aspectos de la vida social que los públicos destinatarios de esas imágenes consideran legítimos, puede afirmarse que la toma de posición del público de la región de Antioquia frente a diversos temas de orden nacional, estaría inspirada en la información contenida en las noticias divulgadas por El Colombiano. Ello se relacionaría con la cotidiana exaltación que sus gentes suelen hacer de "la antioqueñidad" y de la condición de comunidad diferenciada del resto del país, lo que se convertiría en desafío para futuras investigaciones. 


\section{Notas}

(1) Este escrito corresponde al avance de la investigación "El periodismo deportivo en los clásicos del fútbol colombiano y español: el reto de informar, sin sesgos, en sociedades en conflicto".

(2) En la definición de noticia consignada en el Manual de Redacción del periódico El Tiempo, de Bogotá, queda establecido que ella es una narración "objetiva, veraz, completa y oportuna" de acontecimientos de interés general. En tal sentido, el periodista "debe procurar asumir una actitud de distanciamiento crítico", evitando "cualquier opinión personal" frente a los protagonistas del hecho noticioso (El Tiempo, 2000: 47).

(3) La predominancia regional del Partido Conservador en Antioquia desde el siglo XIX garantizó que las reformas impulsadas por los liberales en otras zonas de Colombia se limitaran a los estados dominados por ellos. Por esa razón, los conservadores antioqueños eran "fervorosamente" federalistas porque el federalismo "permitía mantener los intereses de su estado al abrigo de las vicisitudes de la política del resto del país" (González, 2006: 46). El ideario conservador regional sería amplificado por El Colombiano, que desde un principio se autodenominó periódico políticoreligioso, órgano del Directorio Conservador del departamento de Antioquia. Fundado en 1912 por el abogado Francisco de Paula Pérez, en 1930 sería adquirido por los también conservadores Fernando Gómez Martínez y Julio C. Hernández, éste último cuñado de Mariano Ospina Pérez, presidente de Colombia entre 1946 y 1950. Actualmente las familias Martínez y Hernández siguen al frente de este medio y lo han posicionado como "el primer periódico regional del país" (Vallejo Mejía, 2006: 341).

(4) Las élites antioqueñas decimonónicas, adineradas y de marcadas convicciones religiosas, en muchas ocasiones se mantuvieron al margen de las disputas políticas en el resto del territorio nacional con el fin de resguardar la economía regional soportada en la actividad aurífera. Luego, en el siglo XX, emplearían el café como promotor de una industrialización que le daría protagonismo a Antioquia en comparación a otras zonas de Colombia. En otras palabras, desde el siglo XIX, "una elite minera, comercial y de hacendados, predominantemente conservadores, asumió actitudes modernizantes sin entrar en conflicto con la Iglesia y más bien recibió su apoyo. La élite antioqueña conjugó sus actitudes de enriquecimiento con una ética católica y esto hizo que defendiera sus negocios ante cualquier intruso, fuera menos decidida a participar en guerras civiles y más independiente del resto de la nación" (Ortiz, 2010: 44).

(5) La colonización antioqueña es uno de los momentos sobresalientes de la historia económica y social del país. Comprendido entre finales del siglo XVIII e inicios del siglo XX, este fenómeno consistió en el asentamiento de familias antioqueñas en zonas despobladas del occidente colombiano (sur de Antioquia, Caldas, Risaralda, Quindío, norte del Valle del Cauca y norte del Tolima) donde se dedicaron a la producción agrícola en pequeñas parcelas, en particular del café que a la postre sería producto fundamental para el desarrollo económico de Colombia. En esas zonas surgió una sociedad sencilla y democrática, "formada por numerosos propietarios rurales, donde el latifundio fue la excepción, donde las oportunidades de ascenso fueron mayores y donde las distancias y diferencias sociales fueron menores que en otras zonas del país" (Tirado Mejía, 2000: 174). 


\section{Bibliografía}

Bericat Alastuey, E. (2000). La sociología de la emoción y la emoción en la sociología. En Papers-Universidad de Barcelona, 62, pp. 145-176.

Breton, P. (2014). La argumentación en la comunicación. Barcelona: UOC.

Bordes Solanas, M. (2011). Las trampas de circe: falacias lógicas y argumentación informal. Madrid: Cátedra.

Caffi, C. y Janney, R. (1994). Toward a Pragmatics of Emotive Communication. Journal of Pragmatics, 22(3-4), october, pp.325-373.

Calsamiglia Blancafort, H. y Tusón Valls, A. (2001). Las cosas del decir: Manual de análisis del discurso. Barcelona: Ariel.

Castells, M. (2008). La era de la información: economía, sociedad y cultura. Madrid: Alianza.

Crespi, I. (2000). El proceso de opinión pública: Cómo habla la gente. Barcelona: Ariel.

Davison, W. P. (1992). El futuro de la opinión pública en las sociedades democrático liberales. En Rothman, S. (compilador). Los Medios de Comunicación en las sociedades democráticas liberales. Buenos Aires: Devenir.

Fonseca, R. y Prieto de Alizo, L. (2010). Las emociones en la comunicación persuasiva: desde la retórica afectiva de Aristóteles. Quórum Académico-Maracaibo, 7(1), enero-junio, pp. 78-94.

Gómez, L. A. (1982). Opinión pública y medios de difusión. Quito: Ciespal-Fundación Friedrich Ebert.

Gonzalez, F. (2006). Guerras civiles y construcción del Estado en el siglo XIX colombiano. Boletín de Historia y Antiguedades. Bogotá, 93(832), enero-marzo, pp. 31-80.

Guibernau, M. (1996). Los nacionalismos. Barcelona: Editorial Ariel.

Gutiérrez, S. y Plantin Ch. (2010). Argumentar por medio de las emociones: La campaña del miedo del 2006. Versión. Estudios de comunicación y política, 24, México, UAM Xochimilco, pp. 41-69.

Gutiérrez, S. y Reyna Ruiz, M. (2015). El papel de las emociones en la incitación al consumo. Análisis de un programa radiofónico de corte religioso. Nueva época, 23, enero-junio, pp. 125-147.

Hobsbawm, E. (1998). Naciones y nacionalismo desde 1780. Barcelona: Crítica.

López-Aranguren, E. (1995). Las dimensiones de la consciencia nacional y regional. Revista Española de Investigaciones Sociológicas, 71-72, España, pp.41-77. 
McQuail, D. (1998). La acción de los medios: Los medios de comunicación y el interés público. Buenos Aires: Amorrortu.

Miralles, A. M. (2007). Periodismo, opinión pública y agenda ciudadana. Bogotá: Norma.

Nussbaum, M. (2014). Las emociones políticas: ¿Por qué el amor es tan importante para la justicia? Barcelona: Paidós.

Ortiz, L. J. (2010). Obispos, clérigos y fieles en pie de guerra: Antioquia, 1870-1880. Medellín: Universidad Nacional de Colombia-Universidad de Antioquia.

Perelman, Ch. (1997). El imperio retórico: Retórica y argumentación. Bogotá: Norma.

El Tiempo (2000). Manual de redacción. Bogotá: Casa editorial El Tiempo.

Restrepo, L. J. (1995). El mito del gran antioqueño. Pensamiento Humanista, 3, Medellín, Universidad Pontificia Bolivariana, pp.28-33.

Sauvy, A. (1971). La opinión pública. Barcelona: Oikos-Tau.

Santamaría, L. (1990). El comentario periodístico: los géneros persuasivos. Madrid: Paraninfo.

Tirado Mejía, A. (2000). Introducción a la historia económica de Colombia. Bogotá: Ancora.

Vallejo Mejía, M. (2006). A plomo herido: una crónica del periodismo en Colombia, 1880-1980. Bogotá: Planeta.

Van Dijk, T. (1990). La noticia como discurso: comprensión, estructura y comprensión de la información. Barcelona: Paidós.

Vega Reñón, L. (2013). La fauna de las falacias. Madrid: Trotta.

Walton, D. (1992). The place of emotion in argument. Estados Unidos: The Penssylvania State University 